\title{
PEMANFAATAN MEDIA YOUTUBE DALAM MENINGKATKAN PEMAHAMAN PROGRAM KB DI KP KB INSAN SEJAHTERA DESA SUKAJAYA LEMBANG
}

\author{
Dilla Indriasari \\ UPT DP2KBP3A Kecamatan Lembang - Bandung Barat - Jawa Barat - Indonesia \\ dillaindriasari17@gmail.com
}

Received: Februari, 2020; Accepted: Mei, 2020

\begin{abstract}
This study examines the role of the youtube media and understanding of the family planning program, the research problem is how the role of the youtube media in enhancing the understanding of the family planning program. By increasing community participation in the use of KB MKJP. KB counseling is expected to help fertile age cuouples in choosing the right contraception. The use of Non MKJP is very dominating, meaning that many people still do not understand the importance of KB MKJP. Because family planning counseling has not been reached at all levels of society because of the limited extension workers. YouTube media can provide family planning information and help people choose the right contraceptive method for themselves. This study aims to find out the description of the family planning program and how the use of YouTube media in enhancing the understanding of family planning in the Insan Sejahtera family planning family planning company. In this study, researchers used a descriptive method with a qualitative approach. Data collected through interviews, observation and documentation. The population of the study was 327 fertile age cuouples with a sample of 10 fertile age cuouples using Non MKJP. The results showed that youtube media was effective in increasing understanding of the family planning program, as seen from the difference between before and after the introduction of the youtube media. Understanding of the family planning program is demonstrated by community participation in the use of the MKJP.
\end{abstract}

Keywords: Family Planning Program, Youtube Media, Comprehension

\begin{abstract}
Abstrak
Penelitian ini menelaah peran media youtube dan pemahaman program KB, permasalahan penelitian adalah bagaimana peran media youtube dalam meningkatkan pemahaman program KB. Dengan meningkatkan partisipasi masyarakat dalam penggunaan KB MKJP. Penyuluhan KB diharapkan dapat membantu PUS dalam memilih kontrasepsi yang tepat. Penggunaan Non MKJP sangat mendominasi, artinya masyarakat masih banyak yang belum paham pentingnya KB MKJP. Disebabkan penyuluhan KB belum terjangkau pada seluruh lapisan masyarakat karena terbatasnya tenaga penyuluh. Media youtube dapat memberikan informasi KB dan membantu masyarakat dalam pemilihan kontrasepsi yang tepat. Penelitian ini bertujuan untuk mengetahui gambaran program KB dan bagaimana pemanfaatan media Youtube dalam meningkatkan pemahaman KB di KP KB Insan Sejahtera. Dalam penelitian ini peneliti menggunakan metode deskriptif dengan pendekatan kualitatif. Data dikumpulkan melalui wawancara, observasi juga dokumentasi. Adapun yang menjadi populasi penelitiannya adalah 327 PUS dengan sampel 10 PUS yang menggunakan Non MKJP. Hasil penelitian menunjukan media youtube efektif meningkatkan pemahaman program $\mathrm{KB}$, terlihat dari perbedaan antara sebelum dan setelah dikenalkan media youtube. Pemahaman program KB ditunjukan dengan partisipasi masyarakat dalam penggunaan MKJP.
\end{abstract}

Kata Kunci: Program KB, Media Youtube, Pemahaman

How to Cite: Indriasari, D. (2020). Pemanfaatan Media Youtube Dalam Meningkatkan Pemahaman Program KB Di Kampung KB Insan Sejahtera Desa Sukajaya Lembang. CommEdu (Community Education Journal), 3 (2), 115-121. 
116 Indriasari, Pemanfaatan Media Youtube Dalam Meningkatkan Pemahaman Program

KB Di Kampung KB Insan Sejahtera Desa Sukajaya Lembang

\section{PENDAHULUAN}

Berdasarkan Undang-Undang No.52 Tahun 2009 pasal 4 ayat 2 mengenai Perkembangan Kependudukan dan Pembangunan menyatakan Tujuan dari Pembangunan Keluarga yaitu meningkatkan kualitas keluarga guna menimbulkan rasa aman, tenteram, dan juga harapan masa depan yang lebih baik agar terwujudnya kesejahteraan dan kebahagiaan lahir serrta batin.

Sesuai yang diungkapkan Badan Pusat Statistik, peningkatan pertumbuhan penduduk telah menjadi permasalahan. Maka dari itu suatu usaha dari pemerintah dan masyarakat sangat diperlukan. Melalui Program Keluarga Berencana (KB) pemerintah berusaha menekan laju pertumbuhan penduduk.

Keluarga Berencana adalah usaha merencanakan juga mengendalikan penduduk melalui penggunaan metode kontrasepsi dalam upaya menciptakan ekonomi dan sosial bagi seluruh lapisan masyarakat (Saifuddin, 2006).

Dengan meningkatnya penggunaan KB MKJP (Metode kontrasepsi jangka panjang), artinya para wanita sudah memahami kontrasepsi apa yang tepat digunakan bagi dirinya. Melalui penggunaan KB MKJP (Metode kontrasepsi jangka panjang) dapat membantu para pasangan usia subur dalam menunda kehamilan untuk mengatur jarak kelahiran, mengatur jumlah anak yang ideal. Meskipun dalam kenyataanya berbagai hal masih saja dapat menyebabkan kegagalan dalam penggunaann kontrasepsi itu sendiri. Apalagi KB Non MKJP (Metode kontrasepsi jangka pendek) yang lebih rentan tingkat kegagalanya bila dibandingkan dengan KB MKJP (Metode kontrasepsi jangka panjang).

Rentan atau tidaknya kegagalan dalam penggunaan metode kontrasepsi, terlihat dari tingkat drop out pengguna KB Non MKJP (Metode kontrasepsi jangka pendek) yaitu sebesar 23-39\%, sedangkan tingkat drop out pengguna KB MKJP (Metode kontrasepsi jangka panjang) hanya sebesar 0,5-10\% (BAPPENAS, 2012).

Maka dari itu konseling keluarga berencana yang menyeluruh hingga semua lapisan masyarakat sangat diperlukan agar pasangan usia subur memiliki pemahaman yang cukup mengenai pemilihan alat kontrasepsi yang tepat digunakan bagi dirinya, yang tentunya disesuaikan dengan kebutuhan pasangan. Agar tingkat kegagalan penggunaan kontrasepsi dapat menurun guna terwujudnya peningkatan kesejahteraan keluarga.

Berangkat dari kurang menyeluruhnya konseling keluarga berencana (KB) hingga ke semua lapisan masyarakat, pada zaman modern ini media youtube dapat dijadikan solusi dari permasalahan yang ada. Karena Youtube menjadi salah satu dari sekian banyak media sosial yang paling mudah diakses dan juga sangat praktis.

Youtube adalah situs video yang paling populer dikalangan pengguna internet, sehingga sangat sering diakses. Karena youtube memiliki fitur video sharing dimana para pengakses dapat bebas membuka dan melihat video yang tersedia. Ada banyak macam-macam video yang disediakan youtube, mulai dari berbagai video musik, berbagai tutorial-tutorial, dan masih banyak lagi (Asdani, 2008).

Media sosial Youtube menyediakan banyak informasi, salah satunya mengenai program Keluarga Berencana (KB), para PUS (pasangan usia subur) dapat menggali banyak pengetahuan secara praktis lewat video-video yang tersedia di youtube. Baik pengertian dari berbagai metode kontrasepsi, keunggulan, efek samping, biaya pemasangan, faktor apa saja yang harus dipertimbangkan saat sebelum juga pasca pemasangan, tingkat kegagalan dari 
berbagai metode kontrasepsi dan lain sebagainya. Sehingga dengan adanya media youtube, para pasangan usia subur (PUS) tidak akan mengalami lagi kesulitan-kesulitan dalam pemilihan metode kontrasepsi yang tepat.

\section{LANDASAN TEORI}

Pendidikan Nonformal merupakan pendidikan yang diselenggarakan di luar sekolah dengan komunikasi yang teratur juga teraarah. Sehingga peserta didik dalam pendidikan nonformal bisa mendapatkan informasi seputar latihan, pengetahuan juga bimbingan yang disesuaikan dengan berbagai tingkatan usia dan kebutuhan. Pendidikan Nonformal memiliki tujuan agar peserta didik dapat mengembangkan pengetahuan, sikap, ataupun nilai-nilai yang dimilikinya. Sehingga dalam lingkungan pekerjaan, keluarga, masyarakat, ataupun negara, mereka dapat berperan efektif dan efisien Djudju Sudjana (2005).

\section{Pasangan Usia Subur (PUS)}

PUS (Pasangan Usia Subur) merupakan pasangan suami istri dimana istrinya berusia antara 15-49 tahun. Atau pasangan suami istri yang istrinya sudah haid dari sebelum menginjak usia 15 tahun juga pasangan suami istri yang istrinya berusia diatas 49 tahun namun masih haid (Kurniawati, 2014).

\section{Pemanfaatan Media Youtube}

Edisi keempat kamus besar bahasa Indonesia (2010) menyebutkan, pemanfaatan adalah proses, cara, perbuatan memanfaatkan. Pemanfaatan berasal dari kata dasar manfaat yang berarti guna, faedah, laba, untung. Adapun kata memanfaatkan berarti menjadikan ada manfaatnya. Jadi pemanfaatan adalah suatu cara atau perbuatan untuk mendapatkan manfaat.

\section{Pengertian media youtube}

Media pembelajaran adalah suatu alat yang digunakan pada saat kegiatan pembelajaran berlansung dan bertujuan agar membantu proses belajar dan pesan didalamnya supaya dapat mudah dipahami (Meinawati, 2020). Salah satu dari alat bantu pembelajaran yaitu youtube. Youtube adalah situs video yang paling populer dikalangan pengguna internet, sehingga sangat sering diakses. Karena youtube memiliki fitur video sharing dimana para pengakses dapat bebas membuka dan melihat video yang tersedia. Ada banyak macam-macam video yang disediakan youtube, mulai dari berbagai video musik, berbagai tutorial-tutorial, dan masih banyak lagi (Asdani, 2008). Untuk menyebarkan informasi, Youtube menjadi salah satu dari sekian banyak media sosial yang paling mudah diakses juga sangat praktis.

\section{Pemahaman program keluarga berencana (KB)}

Pemahaman atau comprehension adalah kemampuan membaca untuk mengerti suatu ide pokok, pengertian dan detail-detail penting (Pujianti, 2016). Dengan partisipasi dan keterbukaan menjadi kunci dalam pemahaman.

\section{Pengertian program keluarga berencana (KB)}

Undang-undang No.10 Tahun 1992 mengenai perkembangan kependudukan dan pembangunan keluaga sejahtera menyebutkan bahwa melalui pengaturan jarak kelahiran, pendewasaan usia perkawinan, pembinaan ketahanan keluarga, dan peningkatan kesejahteraan keluarga kecil yang bahagia dan sejahtera, Program Keluarga Berencana merupakan salah satu upaya meningkatkan kepedulian juga partisipasi masyarakat. 
Keluarga Berencana adalah usaha merencanakan juga mengendalikan penduduk melalui penggunaan metode kontrasepsi dalam upaya menciptakan kesejahteraan ekonomi dan kesejahteraan sosial bagi seluruh lapisan masyarakat (Saifuddin, 2006).

\section{METODE PENELITIAN}

Dalam penelitian ini peneliti menggunakan metode deskriptif dengan pendekatan kualitatif. Dimana metode penelitian kualitatif merupakan metode yang dilakukan pada kondisi yang alamiah atau natural setting (Sugiyono, 2017). Setelah membuat gambaran yang kompleks, lalu meneliti kata-kata, laporan yang sangat rinci dari pandangan-pandangan responden, peneliti juga melakukan studi pada situasi secara alami. Teknik pengumpulan data dalam penelitian ini yaitu melalui wawancara, observasi, juga dokumentasi. Dan penelitian ini dilakukan di KP KB Insan Sejahtera Kp. Pameceulan RW 06 Desa Sukajaya Kecamatan Lembang Kabupaten Bandung Barat. Dengan populasi atau subjek/objek yang diteliti untuk dipelajari lalu diambil kesimpulannya dalam penenlitian ini 327 pasangan usia subur (PUS) di KP KB Insan Sejahtera Kp. Pameceulan RW 06 Desa Sukajaya Kecamatan Lembang Kabupaten Bandung Barat. Sedangkan sebagian dari populasi yang dijadikan sampel atau dijadikan sebagai objek/subjek penelitian penulis mengambil 10 orang PUS (pasangan usia subur) yang menggunakan KB Non MKJP (metode kontrasepsi jangka pendek). Adapun cakupan teknik analisis data yang digunakan dalam penelitian ini yaitu reduksi data, penyajian data, dan kesimpulan/verifikasi.

\section{HASIL DAN PEMBAHASAN}

\section{Hasil}

Pertama, Pemahaman program keluarga berencana (KB) di KP KB Insan Sejahtera Desa Sukajaya Lembang

Hasil dari penelitian ini menemukan bahwa KP KB Insan Sejahtera mempunyai program keluarga berencana $(\mathrm{KB})$ yang terus berjalan sampai dengan saat ini. Penyuluhan keluarga berencana dilakukan setiap 1 minggu sekali termasuk pada saat pelaksanaan posyandu. Dimana penyuluhan disini dibagi menjadi 2 macam. Ada penyuluhan individu dan penyuluhan kelompok yang diikuti oleh para PUS (pasangan usia subur) baik yang sedang menggunakan KB MKJP (metode kontrasepsi jangka panjang) / KB Non MKJP (metode kontrasepsi jangka pendek) juga diikuti oleh PUS (pasangan usia subur) yang tidak sedang menggunakan KB (Ingin Anak ditunda/Tidak ingin anak lagi). Pemahaman mengenai program keluarga berencana $(\mathrm{KB})$ di KP KB ini masih dikategorikan cukup rendah, terlihat dari partisipasi pasangan usia subur dalam menggunakan KB MKJP (metode kontrasepsi jangka panjang) yang sangat minim bila dibandingkan dengan partisipasi PUS (pasangan usia subur) dalam menggunakan $\mathrm{kb}$ Non MKJP (metode kontrasepsi jangka pendek). Artinya, masih banyak masyarakat yang belum paham mengenai program KB khususnya pentingnya menggunakan KB MKJP (metode kontrasepsi jangka panjang). 
Tabel 1. Jumlah Pasangan Usia Subur (PUS) di KP KB Insan Sejahtera

\begin{tabular}{|c|c|c|c|c|c|}
\hline \multicolumn{4}{|c|}{ PESERTA KB PUS } & \multicolumn{2}{|c|}{$\begin{array}{c}\text { PUS YANG BUKAN } \\
\text { PESERTA KB }\end{array}$} \\
\hline \multicolumn{2}{|c|}{ KB MKJP } & \multicolumn{2}{|c|}{ KB NON MKJP } & \multicolumn{2}{|c|}{ UNMEET NEED } \\
\hline - IUD & 201 & - KONDOM & 13 & - HAMIL & 77 \\
\hline - MOW & 109 & - PIL & 999 & - Ingin anak segera & 125 \\
\hline - MOP & 3 & - SUNTIK & 518 & $\begin{array}{l}\text { - Ingin anak ditunda } \\
\text { - Tidak ingin anak }\end{array}$ & 137 \\
\hline - IMPLANT & 201 & & & lagi & 184 \\
\hline JUMLAH & 514 & JUMLAH & 1530 & JUMLAH & 523 \\
\hline
\end{tabular}

Kedua, Peran media youtube dalam meningkatkan pemahaman program keluarga berencana (KB) di KP KB Insan Sejahtera Desa Sukajaya Lembang

Media youtube efektif dalam meningkatkan pemahaman program KB, dalam hal ini dapat terlihat dari perbedaan antara jumlah peserta $\mathrm{KB}$ awal sebelum dikenalkan media youtube dan jumlah peserta KB setelah dikenalkan media youtube. Dengan menonton berbagai video yang disediakan youtube mengenai metode kontrasepsi $\mathrm{KB}$, pemahaman para pasangan usia subur dapat bertambah. Baik pengertian dari berbagai metode kontrasepsi, keunggulan, efek samping, biaya pemasangan, faktor apa saja yang harus dipertimbangkan saat sebelum juga pasca pemasangan, tingkat kegagalan dari berbagai metode kontrasepsi dan lain sebagainya. Meskipun dengan keterbatasan penyuluh $\mathrm{KB}$ yang tersedia, namun dengan adanya media youtube informasi mengenai KB dapat tetap tersampaikan kepada seluruh lapisan masyarakat sehingga masyarakat menjadi lebih paham mengenai KB. Pemahaman masyarakat mengenai program KB menjadi membaik terlihat dari meningkatnya partisipasi mereka dalam penggunaan metode kontraepsi jangka panjang.

\section{Pembahasan}

Pemahaman atau comprehension adalah kemampuan membaca untuk mengerti suatu ide pokok, pengertian dan detail-detail penting (Pujianti, 2016). Dengan partisipasi dan keterbukaan menjadi kunci dalam pemahaman. Undang-undang No.10 Tahun 1992 mengenai perkembangan kependudukan dan pembangunan keluaga sejahtera menyebutkan bahwa melalui pengaturan jarak kelahiran, pendewasaan usia perkawinan, pembinaan ketahanan keluarga, dan peningkatan kesejahteraan keluarga kecil yang bahagia dan sejahtera, Program Keluarga Berencana merupakan salah satu upaya meningkatkan kepedulian juga partisipasi masyarakat.

Keluarga Berencana adalah usaha merencanakan juga mengendalikan penduduk melalui penggunaan metode kontrasepsi dalam upaya menciptakan ekonomi dan sosial bagi seluruh lapisan masyarakat (Saifuddin, 2006).

Seperti di KP KB Insan Sejahtera program keluarga berencana $(\mathrm{KB})$ yang terus berjalan sampai dengan saat ini yaitu Penyuluhan keluarga berencana yang dilakukan setiap 1 minggu sekali termasuk pada saat pelaksanaan posyandu. Dimana penyuluhan disini dibagi menjadi 2 macam. Ada penyuluhan individu dan penyuluhan kelompok yang diikuti oleh para PUS (pasangan usia subur) baik yang sedang menggunakan KB MKJP (metode kontrasepsi jangka panjang) atau KB Non MKJP (metode kontrasepsi jangka pendek) juga diikuti oleh PUS (pasangan usia subur) yang tidak sedang menggunakan KB (Ingin Anak ditunda/Tidak ingin anak lagi). 
Pemahaman mengenai program keluarga berencana (KB) di KP KB ini masih dikategorikan cukup rendah, terlihat dari partisipasi pasangan usia subur dalam menggunakan metode kontrasepsi jangka panjang (MKJP) yang sangat minim bila dibandingkan dengan partisipasi pasangan usia subur (PUS) dalam menggunakan KB Non MKJP (metode kontrasepsi jangka pendek). Artinya, masih banyak masyarakat yang belum paham mengenai program KB khususnya pentingnya menggunakan KB MKJP (metode kontrasepsi jangka panjang) .

Edisi keempat kamus besar bahasa Indonesia menyebutkan, pemanfaatan adalah proses, cara, perbuatan memanfaatkan. Pemanfaatan berasal dari kata dasar manfaat yang berarti guna, faedah, laba, untung. Adapun kata memanfaatkan berarti menjadikan ada manfaatnya atau ada kegunaanya. Jadi pemanfaatan adalah suatu cara atau perbuatan untuk mendapatkan manfaat.

Youtube adalah situs video yang paling populer dikalangan pengguna internet, sehingga sangat sering diakses. Karena youtube memiliki fitur video sharing dimana para pengakses dapat bebas membuka dan melihat video yang tersedia. Ada banyak macam-macam video yang disediakan youtube, mulai dari berbagai video musik, berbagai tutorial-tutorial, dan masih banyak lagi (Asdani, 2008).Untuk menyebarkan informasi, Youtube menjadi salah satu dari sekian banyak media sosial yang paling mudah diakses juga sangat praktis.

Media youtube efektif dalam meningkatkan pemahaman program $\mathrm{KB}$, dalam hal ini dapat terlihat dari perbedaan antara jumlah peserta $\mathrm{KB}$ awal sebelum dikenalkan media youtube dan jumlah peserta KB setelah dikenalkan media youtube. Baik pengertian dari berbagai metode kontrasepsi, keunggulan, efek samping, biaya pemasangan, faktor apa saja yang harus dipertimbangkan saat sebelum juga pasca pemasangan, tingkat kegagalan dari berbagai metode kontrasepsi dan lain sebagainya.

Dengan adanya media youtube, para PUS (pasangan usia subur) tidak akan mengalami lagi kesulitan-kesulitan dalam pemilihan metode kontrasepsi yang tepat. Meskipun dengan keterbatasan penyuluh $\mathrm{KB}$ yang tersedia, namun dengan adanya media youtube informasi mengenai metode kontrasepsi KB dapat tersampaikan kepada seluruh lapisan masyarakat sehingga masyarakat menjadi lebih paham mengenai metode kontrasepsi KB. Pemahaman masyarakat mengenai program KB menjadi membaik terlihat dari meningkatnya partisipasi mereka dalam penggunaan metode kontraepsi jangka panjang.

\section{KESIMPULAN}

Berdasarkan pemaparan dan hasil penelitian yang telah penulis uraikan di atas, dapat diambil kesimpulan bahwa pemanfaatan media youtube berpengaruh dalam meningkatkan pemahaman PUS (pasangan usia subur) mengenai program keluarga berencana (KB) di KP KB Insan Sejahtera Desa Sukajaya Lembang. Banyak informasi yang didapatkan oleh PUS (pasangan usia subur) dengan menonton berbagai video penyuluhan KB melalui youtube.

Baik pengertian dari berbagai metode kontrasepsi, keunggulan, efek samping, biaya pemasangan, faktor apa saja yang harus dipertimbangkan saat sebelum juga pasca pemasangan, tingkat kegagalan dari berbagai metode kontrasepsi dan lain sebagainya. Selain dapat menambah pemahaman para pasangan usia subur (PUS) media youtube juga dapat membantu pasangan usia subur (PUS) dalam pemilihan metode kontrasepsi yang tepat digunakan bagi dirinya. Sehingga upaya pemerintah dalam meningkatkan kesejahteraan keluarga dapat 
dikatakan berhasil, ditandai dengan meningkatnya partisipasi pasangan usia subur (PUS) dalam penggunaan metode kontrasepsi jangka panjang (MKJP).

\section{DAFTAR PUSTAKA}

Asdani, K. (2008). Belajar Sendiri YouTube (Menjadi Mahir Tanpa Guru). Jakarta: PT Elexmedia Komputindo.

BAPPENAS. (2012). Arah Pembangunan Kependudukan dan Keluarga Berencana dalam RKP 2012 dan Rancangan RKP 2013. Jakarta: BAPPENAS.

Kurniawati, T. (2014). Buku Ajar Kependudukan dan Pelayanan KB. Jakarta: EGC.

Meinawati, K. L. (2020). Pemanfaatan Youtube dalam Meningkatkan Kompetensi Tutor Bimbel Edu Private. Jurnal Comm Edu Vol. 3 No. 1, 19-26.

Pujianti, R. (2016). Peningkatan Pemahaman Membaca Narrative Text Berbahasa Inggris Melalui Scanning Technique Pada Santri Ponpes Miftahul Huda Cimahi.

Empowerment : Jurnal Ilmiah Program Studi Pendidikan Luar Sekolah Vol. 5 No. 2, 33-41.

Saifuddin, A. B. (2006). Buku Panduan Praktis Pelayanan Kontrasepsi. Jakarta: Yayasan Bina Pustaka Sarwono Prawirohardjo.

Sudjana, D. (2005). Metode dan Teknik Pembelajaran Partisipasif dalam Pendidikan Non Formal. Bandung: Falah Production.

Sugiyono. (2017). Metode Penelitian Kuantitatif, Kualitatif, dan R\&D. Bandung: Alfabeta. 